\title{
Acute Pesticide Poisoning among Mixed-crop Agricultural Workers in Thailand
}

\author{
Siriporn Somboon ${ }^{1}$, Ann Jirapongsuwan ${ }^{1, *}$, \\ Surintorn Kalampakorn ${ }^{1}$ and Mathuros Tipyamongkolkul ${ }^{2}$ \\ ${ }^{I}$ Department of Public Health Nursing, Faculty of Public Health, Mahidol University, \\ Bangkok 10400, Thailand \\ ${ }^{2}$ Department of Epidemiology, Faculty of Public Health, Mahidol University, Bangkok 10400, Thailand
}

('Corresponding author's e-mail: ann.jir@mahidol.ac.th)

Received: 8 September 2020, Revised: 10 March 2021, Accepted: 20 March 2021

\begin{abstract}
Since pesticide exposure has acute health effects on agricultural workers and their communities, the research objectives were to describe the factors contributing to acute pesticide poisoning among mixedcrop agricultural workers in Thailand to guide preventive efforts. A cross-sectional survey using a purposive sampling method was conducted among 102 agricultural workers cultivating rice and ornamental plants in Nakhon Nayok province. Each subject was asked to complete a questionnaire on demographics, symptoms and potential associated factors. The questionnaire had a reliability coefficient range of $0.68-0.73$. Logistic regression analysis was used to identify the factors associated with the signs and symptoms of acute health effects from pesticide poisoning. The results showed $56.9 \%$ of the participants to be males with an average age of 51.65 years and $88.2 \%$ to have graduated from primary school. Seventy-eight percent of the participants had experienced acute pesticide poisoning within the month preceding data collection. The most common mild signs of the acute health effects of pesticide poisoning were hot, stinging pain on the skin $(56.3 \%)$, nasal irritation $(56.3 \%)$ and dry throat $(38.8 \%)$. The most common moderate symptoms were nausea/vomiting $(11.8 \%)$, muscle fatigue/weakness $(15.0$ $\%$ ) and chest pain (15.0\%); some workers experienced the severe acute health effect of unconsciousness $(1.3 \%)$. The factors contributing to acute pesticide poisoning were age, years of pesticide use and pesticide poisoning prevention behaviors, all of which were significantly correlated with acute pesticide poisoning among the workers $(p<0.05)$. The findings indicate a need for promoting safe and healthy practice for the mixed-crop agricultural workers in the community. However, recall bias might have occurred from the ability to recall signs and symptoms of agricultural workers.
\end{abstract}

Keywords: Acute pesticide poisoning, Agricultural workers, Mixed-crop agriculture, Pesticide poisoning prevention behavior, Public health

\section{Introduction}

Many countries cultivate mixed crops such as rice, vegetables and fruit, which have pushed farmers to use high amount of pesticides with effects on their health [1]. In Thailand, agricultural workers cultivate mixed crops for increasing income and depend heavily on pesticide use [2]. Nakhon Nayok province is located in the central region of Thailand, and $39.75 \%$ of the informal workers are agricultural workers [3]. Rice cultivation covers every district of the province where planting can take place at least 3 to 5 times in 2 years. The workers cultivate other crops included flowers and ornamental plants with major agricultural products feasible for year-round cultivation. For work processes, the workers use insecticides such as chlorpyrifos, carbosulfan. These activities put agricultural workers at high risk for exposure to pesticides via dermal exposure, ingestion and inhalation [4] resulting in potential risks for pesticide poisoning with both acute and chronic impacts on agricultural workers [5].

The acute health effects include muscarinic and nicotinic effects as well as nervous system disorders [6]. Common mild signs and symptoms include skin irritation, eye irritation and sore throat $[7,8]$. The most common moderate signs and symptoms include muscle fatigue/weakness [7,8]. Studies of rice farmers in Thailand have reported similar mild and moderate of signs and symptoms of pesticide poisoning [9,10], while severe acute health effects such as seizures have also been reported [9]. To 
control agricultural chemicals, the Hazardous Substances Act B.E. 2535 (1992) is established in Thailand. However, this act does not cover actions after the point of sale, thereby resulting in increasing health effects in humans [11].

Rivela reviewed studies on health risks related to pesticide exposure in the agriculture system in Thailand in 2016 in a study on comparing pesticide exposure among the results of rice $[9,12]$ and other crop farmers [13] finding greater risk for exposure in rice farmers than other farmers [14]. In Nakhon Nayok Province, the workers cultivate rice in addition to flowers and ornamental plants, thereby resulting in overlaps in the work process. Consequently, these workers are a high-risk population due to pesticide exposure. To reduce health effects among these workers, health clinics for agricultural workers have been organized [15]. However, the activity has not been continued annually and does not cover all agricultural areas. As an occupational disease, acute pesticide poisoning is caused by individual factors and the toxicology of pesticide poisoning from work conditions and the environment. A comprehensive study of related factors is required, because little is known about acute health effects in agricultural workers who cultivate rice as well as flowers and ornamental plants. Therefore, to reduce the acute health effects of pesticide poisoning, this study was aimed at investigating the signs and symptoms of acute health effects from pesticide poisoning and related factors to guide prevention programs for mixed crop workers.

\section{Materials and methods}

\section{Participants}

A cross-sectional descriptive study using the purposive sampling method was conducted from October to December 2018. The sample size in the study was calculated by using the prevalence of acute health effects [16], and the total projected sample size was 102 selected by simple random sampling based on house numbers. Eight sub-districts cultivate mixed crops in Ongkarak district, Nakhon Nayok province. Srisakrabue, Village 3, was selected by purposive sampling since this area has the highest number of mixed crop workers. The inclusion criteria were agricultural or farm workers, cultivation of mixed crops (rice, flowers and ornamental plants), mixture of chemical substances and spraying pesticides for at least 6 months. The exclusion criteria rejected agricultural workers who did not have responsibilities involving pesticides, were unwilling to participate in the study and were absent on the day the researcher collected data. Written informed consent was obtained from each participant prior to participation. Anonymity was maintained to protect the participants' identity and confidentiality.

\section{Data collection}

After the permission letter was received from the institutional review board on research involving human subjects, the participants were selected based on the inclusion and exclusion criteria. The researcher informed the participants about the research objectives, activities, responsibilities and benefits of the study before their participation in the study. The instruments used for data collection were developed by the researchers, including self-reports and questionnaire concerning pesticide poisoning. The self-report form was developed from 'Self-Reports on the Acute Health Effects of Pesticide Poisoning' (Form I-56) [15] and contained 18 items on 'mild' signs and symptoms of health effects; 10 items on 'moderate' health effects and 3 items on 'severe' health effects. The researchers adjusted this instrument by modifying the checklist of signs and symptoms on the diagram of the body to make it easy for the mixed-crop workers to understand and record their acute health effects. For the factors associated with acute pesticide poisoning, the questionnaire contained the following 4 main domains: 1) socioeconomic and work conditions; 2) knowledge about pesticide poisoning; 3) perception with questions on perceived risks and severity of pesticide poisoning on health; 4) pesticide poisoning prevention. Content validity was examined by 5 experts working in occupational health. Cronbach's alpha coefficient had a range of $0.68-0.73$ among agricultural workers, which was similar to the study participants but not include in the study.

\section{Data analysis}

The data collected were analyzed by using the Statistical Package for the Social Science (SPSS) Version 18.0, for Windows. Descriptive statistic tests were used, including the frequency and percentages of the nominal variables. Mean and standard deviation were used for the continuous variables. The chisquare test analysis was done between the independent (age, gender, education level, knowledge, perception, behaviors and work conditions) and dependent variables (signs and symptoms of acute pesticide poisoning) by using the $p$-value to indicate significant association $(p<0.05)$. In the present study, the researchers conducted binary logistic regression to control the variables with impact on the 
acute health effects of pesticide poisoning. The study was approved by the Human Research Ethics Committee of Mahidol University (Certificate No. MUPH 2017-183) and the Thailand Provincial Health Office (NPHO 2018-013). Written consent was voluntarily obtained from all participants prior to their participation in the study.

\section{Results and discussion}

\section{Socio-demographic profiles}

All eligible participants consented to participate and the response rate for the remaining sample was $100 \%$. The participants comprised $56.9 \%$ males and $43.1 \%$ females. Sixty-nine point five percent of the participants were aged more than 45 years, and the mean age was 51.65 years (S.D. = 10.17). The majority ( $88.2 \%$ ) of the participants had finished primary school and had family incomes exceeding 30,000 baht per year $(88.24 \%$ ) with an average family income of $117,039.22$ baht per year $($ S.D. $=115,220.72)$ (Table 1).

Table 1 Socio-demographic of mixed crop agricultural workers.

\begin{tabular}{|c|c|c|c|c|}
\hline Socio-demographic characteristics & Frequency & Percentage & Mean (S.D.) & (Min, Max) \\
\hline \multicolumn{5}{|l|}{ Gender } \\
\hline Male & 58 & 56.9 & & \\
\hline Female & 44 & 43.1 & & \\
\hline Age (years) & & & 51.65 & $(29,81)$ \\
\hline $25-34$ & 3 & 2.9 & $(10.17)$ & \\
\hline $35-44$ & 18 & 17.6 & & \\
\hline $45-54$ & 42 & 41.2 & & \\
\hline $55-64$ & 27 & 26.5 & & \\
\hline$\geq 60$ & 12 & 11.8 & & \\
\hline \multicolumn{5}{|l|}{ Education Level } \\
\hline Uneducated & 2 & 2.0 & & \\
\hline Primary School & 82 & 80.4 & & \\
\hline Secondary (Jr. High School) & 9 & 8.8 & & \\
\hline Secondary (Sr. High School) & 5 & 4.9 & & \\
\hline Certificate & 1 & 1.0 & & \\
\hline Bachelor Degree & 3 & 2.9 & & \\
\hline Income (Thai baht/year) & & & $117,039.22$ & $(9,000$ \\
\hline$\leq 30,000$ & 12 & 11.8 & $(115,220.72)$ & $600,000)$ \\
\hline $30,001-200,000$ & 78 & 76.5 & & \\
\hline$\geq 200001$ & 12 & 11.7 & & \\
\hline
\end{tabular}

\section{Acute health effects of pesticide poisoning}

A total of 102 participants were enrolled in the study and completed the self-administered questionnaires with assistance from the investigators. Table 2 presents the prevalence and intensity of the self-reported signs and symptoms of the acute health effects of pesticide poisoning in agricultural workers within $48 \mathrm{~h}$. The majority of the pesticide sprayers had experienced symptoms of acute pesticide poisoning in relation to spraying activities during the month preceding data collection. The most common mild symptoms were hot stinging pain on the skin, while nearly half of the mixed-crop workers had nasal irritation and some of the workers had the most common moderate symptoms including nausea/vomiting and muscle fatigue/weakness $(11.8 \%)$. 
Table 2 Signs and symptoms of acute health effects of pesticide poisoning occurring within $48 \mathrm{~h}$ after using pesticides during the previous month.

\begin{tabular}{lll}
\hline Signs and symptoms of acute health effects & Frequency & Percentage \\
\hline Acute Health Effects & 22 & $(21.6)$ \\
No & 80 & $(78.4)$ \\
Yes & & \\
Mild Acute Health Effects & 45 & $(56.3)$ \\
Skin: Hot, Stinging Pain & 45 & $(56.3)$ \\
Nasal Irritation & 31 & $(38.8)$ \\
Sore/Dry Throat & 28 & $(35.0)$ \\
Skin: Itchiness & 27 & $(33.8)$ \\
Dizziness & 26 & $(32.5)$ \\
Eyes: Redness/Irritation & 20 & $(25.0)$ \\
Headaches & 19 & $(23.8)$ \\
Coughing & 15 & $(18.8)$ \\
Difficulty Breathing & 12 & $(15.0)$ \\
Rash/Blistered Skin & & \\
Moderate Acute Health Effects & 12 & $(15.0)$ \\
Nausea/Vomiting & 12 & $(15.0)$ \\
Muscle Fatigue/Weakness & 11 & $(13.8)$ \\
Chest Pain/Tightness & 9 & $(11.2)$ \\
Blurred Vision & 5 & $(6.3)$ \\
Eyelid Twitching & 4 & $(5.0)$ \\
Shaky Hands & 4 & $(5.0)$ \\
Stomachache & 4 & $(5.0)$ \\
Diarrhea & & $(1.3)$ \\
Loss of Consciousness & 1 & \\
Severe Acute Health Effects & & \\
\hline
\end{tabular}

Factors contributing to acute pesticide poisoning in agricultural workers

Knowledge, perception and pesticide poisoning prevention behavior level

Although the majority of the participants had received safety training $(81.4 \%)$, they had low levels of knowledge about pesticide poisoning (19.6\%) with low perceived risks for pesticide poisoning $(22.5 \%)$, low perceived severity of pesticide poisoning (13.7 \%) and low pesticide poisoning prevention behaviors levels (33.3\%) (Table 3).

Table 3 Knowledge level, perception and behaviors of agricultural workers in pesticide poisoning prevention.

\begin{tabular}{|c|c|c|c|c|}
\hline \multirow{2}{*}{\multicolumn{5}{|c|}{$\begin{array}{c}\text { Factors } \\
\text { Received Safety Training }\end{array}$}} \\
\hline & & & & \\
\hline Yes & 83 & (81.4) & & \\
\hline No & 19 & (18.6) & & \\
\hline Knowledge about Pesticide Poisoning & & & $10.45(1.91)$ & $(6,14)$ \\
\hline High & 29 & (28.4) & & \\
\hline Moderate & 53 & $(52.0)$ & & \\
\hline Low & 20 & (19.6) & & \\
\hline Perception about Risks of Pesticide Poisoning & & & $33.19(4.72)$ & $(21,39)$ \\
\hline High & 12 & $(11.8)$ & & \\
\hline Moderate & 67 & $(65.7)$ & & \\
\hline Low & 23 & (22.5) & & \\
\hline Perceived Severity of Pesticide Poisoning & & & $30.17(3.74)$ & $(22,36)$ \\
\hline High & 33 & (32.4) & & \\
\hline Moderate & 55 & (53.9) & & \\
\hline Low & 14 & (13.7) & & \\
\hline Pesticide Poisoning Prevention Behaviors & & & $29.44(6.82)$ & $(16,46)$ \\
\hline High & 22 & (21.6) & & \\
\hline Moderate & 46 & $(45.1)$ & & \\
\hline Low & 34 & (33.3) & & \\
\hline
\end{tabular}


Table 4 shows the preventative practice against pesticide poisoning among the workers. Before pesticide application, majority of the participants reported always performing only hand-washing after mixing pesticides $(79.4 \%)$ and checking tanks and spraying equipment $(79.4 \%)$. They also reported sometimes of reading label instructions $(76.5 \%)$. However, the $67.6 \%$ of the participants reported never wearing rubber gloves, never wore masks $(74.5 \%)$ and never used eye protection $(91.2 \%)$. During pesticide application, the majority of the participants reported always wearing long-sleeved shirts covering the arms and neck $(97.1 \%)$, long pants $(82.4 \%)$, masks $(94.1 \%)$ and hats $(92.1 \%)$ with no smoking (98.0\%), no drinking (74.55\%), standing up wind (94.1\%) and no use of blocked nozzles $(90.2$ $\%$ ). While, $72.5 \%$ of the participants reported never using rubber gloves, while $92.1 \%$ never used pouches and $81.4 \%$ never wore boots. After pesticide application, the majority of the participants reported always cleaning spraying equipment $(83.3 \%)$, cleansing the body $(88.2 \%)$, separating and laundering clothing $(83.3 \%)$ and selling agricultural products following Restricted-Interval-Times (69.7 $\%)$. They reported sometimes disposing of pesticides in rice fields and ornamental plants $(72.5 \%)$ and disposal of pesticide containers following instructions $(63.7 \%)$; 93.1 percent of the participants reported never posting warning labels for spraying equipment and pesticide storage.

Table 4 Pesticide poisoning prevention behaviors in agricultural workers $(n=102)$.

\begin{tabular}{|c|c|c|c|}
\hline \multirow{2}{*}{ Pesticide poisoning prevention behaviors } & \multicolumn{3}{|c|}{ Number (\%) } \\
\hline & Always & Sometimes & Never \\
\hline \multicolumn{4}{|l|}{ Before Pesticide Application } \\
\hline Reading Label Instructions & $19(18.6)$ & $78(76.5)$ & $5(4.9)$ \\
\hline Wearing Rubber Gloves & $18(17.6)$ & $15(14.7)$ & $69(67.6)$ \\
\hline Wearing a Mask & $22(21.6)$ & $4(3.9)$ & $76(74.5)$ \\
\hline Eye Protection & $1(1.0)$ & $8(7.8)$ & $93(91.2)$ \\
\hline Use of Wood to Mix Chemicals & $38(37.3)$ & $55(53.9)$ & $9(8.8)$ \\
\hline Hand-washing after Mixing Pesticides & $81(79.4)$ & $19(18.6)$ & $2(2.0)$ \\
\hline Checking Tank Leaks and Spraying Equipment & $81(79.4)$ & $21(20.6)$ & $0(0)$ \\
\hline \multicolumn{4}{|l|}{ During Pesticide Application } \\
\hline Rubber Gloves & $15(14.5)$ & $13(12.7)$ & $74(72.5)$ \\
\hline Long-sleeved Shirts Covering the Arms and Neck & $99(97.1)$ & $3(2.9)$ & $0(0)$ \\
\hline Long Pants & $84(82.4)$ & $15(14.7)$ & $3(2.9)$ \\
\hline Mask & $96(94.1)$ & $6(5.9)$ & $0(0)$ \\
\hline Hat & $94(92.1)$ & $7(6.9)$ & $1(1.0)$ \\
\hline Use of a Pouch & $1(1.0)$ & $7(6.9)$ & $94(92.1)$ \\
\hline Boots & $3(2.9)$ & $16(15.7)$ & $84(81.4)$ \\
\hline No Smoking & $100(98.0)$ & $1(1.0)$ & $1(1.0)$ \\
\hline No Eating & $97(95.1)$ & $2(2.0)$ & $3(2.9)$ \\
\hline No Drinking & $76(74.5)$ & $20(19.6)$ & $6(5.9)$ \\
\hline Standing Upwind & $96(94.1)$ & $5(4.9)$ & $1(1.0)$ \\
\hline Use of Blocked Nozzles & $92(90.2)$ & $6(5.9)$ & $4(3.9)$ \\
\hline \multicolumn{4}{|l|}{ After Pesticide Application } \\
\hline Disposal pesticides in agricultural area & $11(10.8)$ & $74(72.5)$ & $17(16.7)$ \\
\hline Disposal of Pesticide Containers & $12(11.8)$ & $65(63.7)$ & $25(24.5)$ \\
\hline Cleaning of Spraying Equipment & $85(83.3)$ & $17(16.7)$ & $0(0)$ \\
\hline Cleansing of the Body & $90(88.2)$ & $10(9.8)$ & $2(2.0)$ \\
\hline Separating and Laundering Clothing & $85(83.3)$ & $17(16.7)$ & $0(0.0)$ \\
\hline Warning Label at Pesticides storage & $1(1.0)$ & $6(5.9)$ & $95(93.1)$ \\
\hline $\begin{array}{l}\text { Sale Agricultural Products follow Restrict-Interval- } \\
\text { Times }\end{array}$ & $69(69.7)$ & $29(29.3)$ & $1(1.0)$ \\
\hline
\end{tabular}

\section{Work conditions of agricultural workers}

Table 5 shows that $99.0 \%$ of the participants were farm owners involved in mixing, loading and application of pesticides. With regard to years of pesticide use, the participants had used pesticides for 2 - 50 years, and $39.2 \%$ of them had used pesticides for $11-20$ years with a mean pesticide usage $=21.93$ years (S.D. $=9.58)$. The participants used several pesticides such as insecticides $(100 \%)$, herbicides $(98 \%)$ and fungicides $(96.1 \%)$. For frequency of spraying in cultivating rice, the participants planted approximately 1 
to 3 rounds per year and applied pesticides 1 - 10 times per round. For flower and ornamental plant cultivation, the participants planted year-round and applied pesticides 1 - 7 times per month. Regarding time spent in daily pesticide application in the work process for cultivating rice, the participants spent $30-350$ min in pesticide application per time, and most of the participants spent $61-120 \mathrm{~min} /$ time $(44.1 \%)$. For flower and ornamental plant cultivation, the participants spent $40-360$ min per time, and most of the participants spent less than $120 \mathrm{~min} /$ time in pesticide application $(63.7 \%)$.

Table 5 Work conditions of agricultural workers.

\begin{tabular}{|c|c|c|c|c|}
\hline Work conditions & $\begin{array}{c}\text { Frequency } \\
(\mathrm{n}=102)\end{array}$ & Percentage & $\begin{array}{r}\text { Mean } \\
\text { (S.D) }\end{array}$ & (Min, Max) \\
\hline Years of Pesticide Use & & & $\begin{array}{l}21.93 \\
(9.58)\end{array}$ & $(2,50)$ \\
\hline Less than 10 years & 27 & 26.5 & & \\
\hline More than 20 & 75 & 73.5 & & \\
\hline \multicolumn{5}{|l|}{ Types of Pesticides Used } \\
\hline Insecticides & 102 & 100.0 & & \\
\hline Herbicides & 100 & 98.0 & & \\
\hline Fungicides & 98 & 96.1 & & \\
\hline \multicolumn{5}{|l|}{$\begin{array}{l}\text { Frequency of Spraying for Rice Cultivation } \\
\text { (times/cycle) }\end{array}$} \\
\hline Less than 3 times & 9 & 8.82 & & \\
\hline More than 3 times & 93 & 91.18 & & \\
\hline $\begin{array}{l}\text { Time Spent in Pesticide Applications per Day } \\
\text { for Rice Cultivation }\end{array}$ & & & $\begin{array}{l}137.70 \\
(51.18)\end{array}$ & $(30,300)$ \\
\hline Less than $60 \mathrm{~min}$ & 6 & 5.9 & & \\
\hline $61-120 \mathrm{~min}$ & 45 & 44.1 & & \\
\hline $121-180 \mathrm{~min}$ & 43 & 42.2 & & \\
\hline More than $181 \mathrm{~min}$ & 8 & 7.8 & & \\
\hline \multicolumn{5}{|l|}{$\begin{array}{l}\text { Frequency of Spraying for Planting Flowers } \\
\text { and Ornamental Plants (times/month) }\end{array}$} \\
\hline $1-3$ times & 66 & 64.7 & & \\
\hline More than 3 times & 36 & 35.3 & & \\
\hline $\begin{array}{l}\text { Time Spent in Pesticide Application per Day } \\
\text { for Flowers and Ornamental Plants }\end{array}$ & & & $\begin{array}{l}131.03 \\
(67.28)\end{array}$ & $(40,360)$ \\
\hline Less than $60 \mathrm{~min}$ & 13 & 12.7 & & \\
\hline $61-120 \min$ & 52 & 51.0 & & \\
\hline $121-180 \mathrm{~min}$ & 26 & 25.5 & & \\
\hline More than $181 \mathrm{~min}$ & 11 & 10.8 & & \\
\hline
\end{tabular}

Factors associated with acute pesticide poisoning among agricultural workers

According to the criteria, any predictor variable whose bivariate test has a $p$-value of less than 0.25 was considered a candidate in the model [17] in which 4 factors remained: Age, perception of the risks for pesticide poisoning, pesticide poisoning prevention behaviors and years of pesticide use. The backward method was used to find a better fitting model; the variables with $p$-values exceeding 0.05 were excluded from the model. The Hosmer and Lemshow test showed non-statistical significance $(p=0.764)$, meaning that the model fits well with the data. Based on all the exposures evaluating its relationship to pesticide poisoning, after controlling for other variables, 3 of the 4 (age, pesticide poisoning prevention behaviors and years of pesticide use) showed statistically significant associations with the outcome. The multiple logistic regression model is presented below:

$\ln \left(\frac{p}{1-p}\right)=-0.060-1.663 \mathrm{X}_{1}+0.905 \mathrm{~A}_{1}+1.569 \mathrm{~A}_{2}+2.660 \mathrm{X}_{2}$ 
Table 6 presents that the risks for pesticide poisoning among the mixed crop agricultural workers aged between $41-60$ years old is 4.8 times greater than the risk among agricultural workers aged over 60 years by adjusting for pesticide poisoning prevention behaviors and years of pesticide use. For pesticide poisoning prevention behaviors, the risks for pesticide poisoning among the mixed crop agricultural workers who practiced pesticide poisoning prevention behaviors at a low level was 14.30 times greater than the agricultural workers who practiced pesticide poisoning prevention behaviors at moderate and high levels by adjusting for age and years of pesticide use. For work conditions, the risks for pesticide poisoning among the mixed crop workers who had more than 10 years of pesticide use was 0.81 times greater than the agricultural workers who had pesticide use of under 10 years.

Table 6 Predictors of experience with acute pesticide poisoning among agricultural workers by using multiple logistic regression analysis.

\begin{tabular}{lllllll}
\hline Covariate & B & S.E. & Wald & df & Sig. & Exp (B) \\
\hline $\begin{array}{l}\text { Constant } \\
\text { Years of Pesticide Use }\left(\mathrm{X}_{1}\right)\end{array}$ & -0.060 & 0.504 & 0.014 & 1 & 0.906 & 0.942 \\
$\quad$ Less than 10 years & -1.663 & 0.792 & 4.413 & 1 & 0.036 & 0.19 \\
$\quad$ More than 10 years & & & & & & \\
Age & 0.905 & 0.9 & 1.011 & 1 & 0.315 & 2.472 \\
$\quad$ Less than 40( $\left.\mathrm{A}_{1}\right)$ & 1.569 & 0.641 & 5.984 & 1 & 0.014 & 4.8 \\
$\quad$ 41 - 60 $\left(\mathrm{A}_{2}\right)$ & & & 6.047 & 2 & 0.049 & \\
$\quad \begin{array}{l}\text { More than 60 (ref) } \\
\text { Pesticide Poisoning Prevention Behaviors }\left(\mathrm{X}_{2}\right)\end{array}$ & 2.660 & 1.064 & 6.249 & 1 & 0.012 & 14.30 \\
$\quad$ Low & & & & & & \\
$\quad$ Moderate-High & & & & & & \\
\hline
\end{tabular}

\section{Discussion}

In this study, the occurrence of acute health effects of pesticide poisoning $(74.8 \%)$ were higher than the morbidity rate for pesticide poisoning from occupational and environment-related reports (17.12/100,000 persons) [18]. This may be related to underreporting of acute health effects and inadequate legislation to control pesticide use [11]. When compared with previous studies, the prevalence was higher than studies conducted in Turkey (40.6\%) [5], Zimbabwe (45.1\%) [8] and Argentina (47.7 $\%$ ) [19] as well as previous studies in Thailand (50\%) [10]. This finding may be related to previous studies involving less time in pesticide spraying and fewer numbers and types of pesticides used [19], different types of farming [10] and different questionnaires for reporting signs and symptoms $[5,8]$.

In this study, the most common mild signs and symptoms included skin and respiratory signs and symptoms such as hot stinging pain on the skin and nasal irritation. Moderate signs and symptoms were fatigue/weakness and nausea/vomiting. Only $1 \%$ reported unconsciousness, whereas other studies did not have reports on severe acute health effects [9]. This finding may be related to the pesticide exposure of mixed-crop workers in their work processes. The most popular insecticides used among the participants are chlopyrifos (organophosphate) and carbosulfan (carbamate) for which the initial signs and symptoms include eye, skin, or respiratory system irritation [20] and inhibited acetylcholinesterase [21] leading to the neurological effects of moderate and severe signs and symptoms presented in the current study.

The factors affecting occupational diseases such as age, pesticide poisoning prevention behaviors and years of pesticide use had statistically significant associations with the outcome in this study. Age ( $>40$ years) was associated with the occurrence of acute pesticide poisoning. Similar to the findings of a previous study in Cambodia [7], increasing age leads to a gradual decrease in physical and mental capacity [5]. Furthermore, the workers in our study continued to work in the agricultural sector because there was no transfer from generation-to-generation as in the past. Consequently, the workers were aging and represented a high-risk group due to long-term pesticide exposure.

Concerning work conditions, exposure to pesticides for more than 10 years was associated with acute pesticide poisoning among workers. These findings are similar to the findings of studies among agricultural workers in the Cambodia [7] and Argentina [19]. This may be related to the fact that most of the workers continued to work in the agricultural sector with a mean pesticide usage of approximately 21 
years resulting in deteriorated physical health $[10,22]$ and low pesticide poisoning prevention behavior levels $(33.3 \%)$ leading to acute pesticide poisoning among workers.

According to the findings, low levels of pesticide poisoning prevention behaviors are associated with the prevalence of acute pesticide poisoning among workers. Consistent with the findings of previous studies, the workers who had low levels of pesticide poisoning prevention behaviors did not follow pesticide labels [1,23], while less than $50 \%$ of the workers wore gloves, masks or boots while spraying pesticides [1] and there was no restricted re-entry interval times and sub-standard disposal of empty containers [9]. The above findings may be related to the fact agricultural workers always used the same pesticides. As a result, they do not pay attention to the pesticide labels, find it inconvenient to use some PPE such as boots in rice paddies and use cloth masks due to ready availability. In addition, the participants did not follow restricted interval times. Therefore, promoting pesticide poisoning behaviors before-during-after pesticide application is of great importance.

There were limitations in our study. This study targeted workers cultivating rice as well as flowers and ornamental plants. Therefore, the findings cannot be generalized among all mixed crops with differences in working processes. In addition, the signs and symptoms of acute health effects on agricultural workers after using pesticides within $48 \mathrm{~h}$ in the previous month were self-reported. Thus, recall bias might have occurred due to the possible inability of the agricultural workers to recall signs and symptoms. To ease this difficulty, the researchers suggest the addition of photographs for recording the signs and symptoms of acute pesticide poisoning and further study to collect strong evidence on the ease of using photographic checklists.

\section{Conclusions}

This study reveals that the prevalence of the acute health effects of pesticide poisoning among mixed-crop agricultural workers was reported to be higher than in previous studies and associated with the ages of the workers, years of pesticide use and relatively low scores for pesticide poisoning prevention behaviors. Future research may focus on promoting practice such as proper pesticide poisoning prevention behaviors to reduce negative health effects, promotion of safe pesticide use strategies, enhancement of PPE use and personal hygiene in workers, while the key policy implication suggests improvement in the monitoring and control of pesticide usage and disposal of containers at the community level.

\section{Acknowledgements}

The authors would like to express their deep appreciation for all of the mixed-crop agricultural workers who participated in this study. We would also like to thank the public health officers who assisted in facilitating this research. This research was financially supported by the Mahidol Alumni, Mahidol University and Srinakarintarawirot University, Thailand.

\section{References}

[1] D Öztaş, B Kurt, A Koç, M Akbaba and H İlter. Knowledge level, attitude, and behaviors of farmers in Çukurova region regarding the use of pesticides. Biomed Res. Int. 2018; 1, 1-8.

[2] C Grovermann, P Schreinemachers and T Berger. Quantifying pesticide overuse from farmer and societal points of view: An application to Thailand. J. Crop Prot. 2013; 53, 161-8.

[3] Provincial Labour Office Nakhon Nayok. Report of labour sistuation, Available at: https://nakhonnayok.mol.go.th/news_group/labour_situation, accessed January 2021.

[4] C Lesmes-Fabian and CR Binder. Pesticide flow analysis to assess human exposure in greenhouse flower production in Colombia. Int. J. Environ. Res. Public Health 2013; 10, 1168-85.

[5] H Çakmur. Health risks faced by Turkish agricultural workers. Sci. World J. 2014; 2014, 1-8.

[6] JR Patil, VM Motghare, SL Padwal, VS Deshmukh, SS Rathod and RR Pore. Agricultural pesticide poisoning. Indian J. Medical Spec. 2013; 4, 266-77.

[7] A Thetkathuek, N Suybros, W Daniell, P Meepradit and W Jaidee. Factors influencing poisoning symptoms: A case study of vegetable farmers exposed to mixed insecticides in Prek Balatchheng village, Cambodia. J. Agromedicine 2014; 19, 337-45.

[8] R Magauzi, B Mabaera, S Rusakaniko, A Chimusoro, N Ndlovu, M Tshimanga, G Shambira, A Chadambuka and $\mathrm{N}$ Gombe. Health effects of agrochemicals among farm workers in commercial farms of Kwekwe district, Zimbabwe. Pan Afr. Med. J. 2011; 9, 1-8. 
[9] R Sapbamrer and S Nata. Health symptoms related to pesticide exposure and agricultural tasks among rice farmers from northern, Thailand. Environ. Health Prev. Med. 2014; 19, 12-20.

[10] K Pidgunpai, S Keithmaleesatti and W Siriwong. Knowledge, attitude and practice associated with cholinesterase level in blood among rice farmers in Chainart province, Thailand. J. Health Res. 2017; 28, 93-9.

[11] P Panuwet, W Siriwong, T Prapamontol, PB Ryan, N Fiedler, MG Robson and DB Barr. Agricultural pesticide management in Thailand: Status and population health risk. Environ. Sci. Policy. 2012; 17, 72-81.

[12] E Sombatsawat, S Norkaew and W Siriwong. Blood cholinesterase level as biomarker of organophosphate and carbamate pesticide exposure effect among rice farmers in Tarnlalord subdistrict, Phimai district, Nakhon Ratchasima province, Thailand. J. Health Res. 2014; 28, S33-S40.

[13] N Taneepanichskul, S Norkaew, W Siriwong and M Robson. Health effects related to pesticide using and practicing among Chilli-growing farmers, Northeastern, Thailand. J. Med. Med. Sci. 2011; 3, 319-25.

[14] EP Rivera, W Siriwong, N Taneepanichskul, S Norkaew and MG Robson. Health risk related to pesticide exposure in the agriculture system in Thailand: A systematic review. J. Health Res. 2016; 30, 71-80.

[15] Bureau of Occupational and Environmental Diseases. Manual of occupational health services for public health officer; health clinic for agricultural worker Bangkok: Ministry of Public Health, Printing Agricultural Cooperative Federation of Thailand, Available at: http://envocc.ddc.moph.go.th/contents?g=4\&s=1, accessed April 2016.

[16] J Charan and $\mathrm{T}$ Biswas. How to calculate sample size for different study designs in medical research? Indian J. Psychol. Med. 2013; 35, 121-6.

[17] DW Hosmer, S Lemeshow and RX Sturdivant. Applied logistic regression. $3^{\text {rd }}$ eds. Wiley, New Jersey, 2013.

[18] Bureau of Epidemiology. Reporting of occupational and environmental diseases surveillance between 2018, Available at: http://envocc.ddc.moph.go.th/uploads/situation2/2561/2561_01_envocc_ situation.pdf, accessed June 2014.

[19] M Butinof, RA Fernandez, MI Stimolo, MJ Lantieri, M Blanco, AL Machado, G Franchini and PD Mdel. Pesticide exposure and health conditions of terrestrial pesticide applicators in Cordoba province, Argentina. Cad. Saude Publica 2015; 31, 633-46.

[20] National Pesticide Information Center. Insecticides: Chemistries and characteristics, Available at: http://npic.orst.edu/, accessed September 2019.

[21] CD Klaassen, LJ Casarett and J Doull. Casarett and Doull's toxicology: The basic science of poisons. $8^{\text {th }}$ eds. McGraw-Hill Education, New York, 2013.

[22] B Raksanam, S Taneepanichskul, MG Robson and W Siriwong. Health risk behaviors associated with agrochemical exposure among rice farmers in a rural community, Thailand: A communitybased ethnography. Asia Pac. J. Public Health 2014; 26, 588-95.

[23] K Ji-Hyun, K Jaeyoung, C Eun Shil, K Yousun, K Doo Hwan and L Won Jin. Work-related risk factors by severity for acute pesticide poisoning among male farmers in South Korea. Int. J. Environ. Res. Public Health 2013; 10, 1100-12. 